\title{
Effects of Oxidation of Carbon Black Surface on the Properties of Carbon Black-Natural Rubber Systems
}

\author{
Hajime Serizawa, Takehusa NaKamura, Masayoshi Ito, \\ Koji TANAKA, and Akimasa NOMURA* \\ Department of Chemistry, Faculty of Science, \\ Science University of Tokyo, \\ Kagurazaka, Shinjuku-ku, Tokyo 162, Japan \\ ${ }^{*}$ Research \& Development Center, Nippon Zeon Co., Ltd., \\ Yako, Kawasaki-ku, Kawasaki, Kanagawa 210, Japan
}

(Received September 22, 1982)

\begin{abstract}
Proton spin-spin relaxation time $\left(T_{2}\right)$ was measured by the pulsed NMR technique for bound rubbers in composites prepared from natural rubber and carbon black at different acid group concentrations. The bound rubber consisted of loosely and tightly bound rubbers. By incorporation of the oxidized carbon black with a high concentration of acid groups into natural rubber, the content of the total bound rubber in the composite increased, and the segmental mobility of the loosely and tightly bound rubber constituting the bound rubber was enhanced. The increase in the segmental mobility of the bound rubber and its content resulted from the formation of the bound rubber with fairly long loops on the oxidized carbon black. The change in reactivity of the carbon black brought about nitric acid treatment is also discussed in connection with the results mentioned above.
\end{abstract}

KEY WORDS Natural Rubber / Carbon Black / Oxidation / Acid Groups / Pulsed NMR / Spin-Spin Relaxation Time / Segmental Mobility / Tightly Bound Rubber / Loosely Bound Rubber /

It is well known that the incorporation of surface active carbon black into various kinds of rubber produces a significant amount of bound rubber due to strong interactions between the active carbon black and rubber segments. ${ }^{1}$ Although the mechanism of bound rubber formation had been studied extensively using various kinds of elastomers and fillers with a wide range of surface characteristics, ${ }^{2-7}$ explanations for the results are sometimes contradictory. Gessler ${ }^{4}$ studied the reinforcement of butyl rubber with oxidized carbon black and observed a large increase in bound rubber content in the composite. This was explained by the increase in the general reactivity of the oxidized carbon black. On the other hand, Hess et al. ${ }^{7}$ suggested on the basis of adhesion index data on oxidized and unoxidized carbon black-rubber systems that the reactivity of the carbon black decreased by oxidation. It has been reported that the bound rubber structure is greatly affected by the preparation conditions of the composite. ${ }^{8,9}$ Thus detailed information regarding the structure of bound rubber seems to be necessary for understanding the effects of the surface modification of carbon black on the properties of the composite.

Pulsed NMR studies have provided important information on the structure of bound rubber phases produced by mechanical mixing. ${ }^{10,11}$ In the present study, pulsed NMR measurements were carried out for bound rubber in a composite prepared from natural rubber and carbon black with different acid group concentrations. The results are discussed in terms of the surface modification effects of the carbon black on the structure of bound rubber in the composite.

\section{EXPERIMENTAL}

\section{Samples}

The carbon black and rubber used in this study 
were Diablack A (Mitsubishi Chemicals Co. Ltd.) of SAF grade and Pale crepe (natural rubber), respectively. The oily matter on the Diablack A was extracted with benzene for at least $50 \mathrm{~h}$ in a Soxhlet extractor and then the carbon black (unoxidized carbon black) was dried at $100^{\circ} \mathrm{C}$ in vacuo. The oxidative treatment of the original carbon black was carried out with nitric acid under various conditions for different oxidation times, temperatures and nitric acid concentrations. The oxidized carbon black was washed with distilled water several times to remove the nitric acid and then with acetone. It was dried at $100^{\circ} \mathrm{C}$ in vacuo. The details of the composite preparations are described in our earlier paper. ${ }^{9}$ The intensity of the NMR signals by the bound rubber phase in the composite was weak compared with that from the nonbound rubber phase. In order to obtain more accurate values for the ralaxation time and fraction of the bound rubber phase in the composite, only carbon gel (bound rubber plus carbon black) was prepared for NMR measurements by the following method. The compoite was cut into small pieces (about $2 \mathrm{~mm}$ in diameter) approximately $2 \mathrm{~g}$ of which was loosely packed in a cage of 150 mesh size. The cage was immersed in a sufficiently large amount of toluene (about $400 \mathrm{~cm}^{3}$ ) and extraction was carried out at room temperature for $72 \mathrm{~h}$. There was no indication of leaching out of the carbon black during the extraction. The carbon gel was suspended in acetone to exchange the toluene with the more volatile solvent and then filtered. The gel was dried in vacuo at room temperature for a week.

\section{Measurement}

Pulsed NMR measurements were performed with a JEOL pulsed NMR spectrometer (JSE-5B), operating at $60 \mathrm{MHz}$. Proton spin-spin relaxation time $\left(T_{2}\right)$ was obtained by a solid echo sequence, ${ }^{12}$ which provided a good approximation of free induction decay, with a pulse width of $2 \mu$ s and a pulse interval of $9 \mu \mathrm{s}$. The solid echo signals were accumulated with a time-averaging computer to improve the signal to noise ratio. The spin-spin relaxation time and the fraction of each component were determined by the method described in a previous paper. ${ }^{9}$ The samples were packed in a glass tube and sealed in vacuo.

\section{RESULTS AND DISCUSSION}

\section{Characterization of Carbon Black}

The neutralization technique reported by $\operatorname{Rivin}^{13}$ was used to determine the acid group concentrations of the carbon black. The concentrations of the total and strong acid groups were obtained by base adsorption in aqueous solutions of sodium hydroxide and sodium bicarbonate, respectively. The concentration of weak acid groups was determined by subtracting the strong acid concentration from the total acid concentration. The surface area of the carbon black was determined by the B.E.T. method of nitrogen adsorption. The oxidation conditions of the carbon black, and the resultant surface area and acid group concentrations are shown in Tables Ia and Ib, respectively. Strong and weak acid groups corresponding to carboxyl and hydroxyl groups, respectively ${ }^{13}$ are produced by oxidative treatment with nitric acid. The concentrations of both groups obviously change with oxidation time and temperature as

Table I(a). Oxidation conditions for Carbon Black

\begin{tabular}{|c|c|c|c|}
\hline Carbon & $\mathrm{HNO}_{3}$ Concentration & Temperature & Time \\
\hline No. & $\mathrm{mol} \mathrm{dm}^{-3}$ & ${ }^{\circ} \mathrm{C}$ & $\mathrm{h}$ \\
\hline 1 & \multicolumn{3}{|c|}{ Original Carbon Black } \\
\hline 2 & 1.7 & 25 & 3 \\
\hline 3 & 1.7 & 60 & 1 \\
\hline 4 & 1.7 & 100 & 1 \\
\hline 5 & 1.7 & 100 & 3 \\
\hline 6 & 4.5 & 100 & 2.5 \\
\hline 7 & 4.5 & 100 & 3 \\
\hline
\end{tabular}

Table I(b). Characteristics of Carbon Black

\begin{tabular}{|c|c|c|c|c|}
\hline \multirow{2}{*}{$\begin{array}{c}\text { Carbon } \\
\text { Black } \\
\text { No. }\end{array}$} & \multirow{2}{*}{$\frac{\text { Surface area }}{\mathrm{m}^{2} \mathrm{~g}^{-1}}$} & \multicolumn{3}{|c|}{$\begin{array}{c}\text { Acid group } \\
\text { concentration } / \mathrm{mmolg}^{-1}\end{array}$} \\
\hline & & $\begin{array}{l}\text { Total } \\
\text { acids }\end{array}$ & $\begin{array}{c}\text { Strong } \\
\text { acids }\end{array}$ & $\begin{array}{l}\text { Weak } \\
\text { acids }\end{array}$ \\
\hline 1 & $133 \pm 4$ & 0.14 & 0.00 & 0.14 \\
\hline 2 & $125 \pm 4$ & 0.20 & 0.07 & 0.13 \\
\hline 3 & $121 \pm 4$ & 0.27 & 0.06 & 0.21 \\
\hline 4 & $125 \pm 3$ & 0.43 & 0.09 & 0.34 \\
\hline 5 & $127 \pm 3$ & 0.49 & 0.15 & 0.34 \\
\hline 6 & $139 \pm 3$ & 0.65 & 0.23 & 0.42 \\
\hline 7 & $145 \pm 4$ & 0.73 & 0.20 & 0.53 \\
\hline
\end{tabular}


well as nitric acid concentration. However, almost no change in surface area was observed by oxidations carried out under various conditions. Similar results have been reported by Suzuki et al. ${ }^{14}$ Although we obtained strong and weak acid concentrations individually, the NMR data were more sensitive to the total acid group concentration than to indivividual concentrations. Therefore, all NMR data were correlated with the total acid group concentration in the following section.

\section{Brabender Mixing}

Figure 1 shows typical Brabender traces for mixing processes of natural rubber and unoxidized carbon black, and of natural rubber and oxidized carbon black at $120^{\circ} \mathrm{C}$ and $30 \mathrm{rpm}$. Up to $1.5 \mathrm{~min}$, each trace shows a decrease in torque due to a rise in batch temperature and volume contraction. After $1.5 \mathrm{~min}$, the torque for mixing the unoxidized carbon black and natural rubber decreases very slowly, whereas the torque for mixing the oxidized carbon black and natural rubber increases steadily with time. This fact indicates that the viscosity of the composite prepared from the oxidized carbon black and rubber is high compared with that prepared from the unoxidized carbon black and rubber. The increase in viscosity suggests an increase in the bound rubber content in filled rubber. ${ }^{6}$ On the basis of these findings, it seems that the bound rubber content in the composite prepared from the oxidized carbon black and rubber is larger than that prepared from the unoxidized carbon black and rubber. As shown in Table Ib, the concentration of

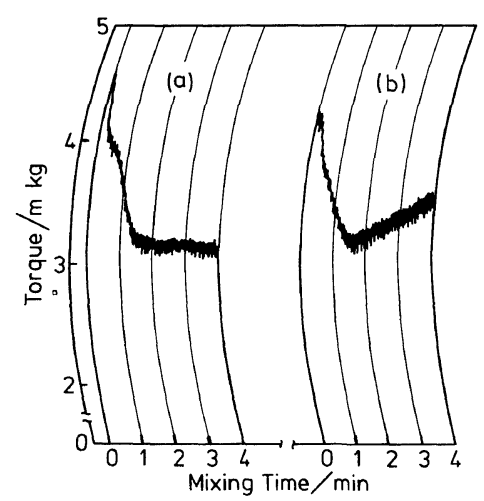

Figure 1. Brabender Plastograph mixing curves at $120^{\circ} \mathrm{C}$ and $30 \mathrm{rpm}$ for the composites: (a), natural rubber and unoxidized carbon black; (b), natural rubber and oxidized carbon black (Carbon Black No. 7). the acid group on the carbon black increased appreciably, whereas the surface area remained almost unchanged by oxidation. Therefore, the increase in bound rubber content seems to be induced primarily by incorporation of the oxidized carbon black with a high concentration of acid groups into natural rubber. In a later section of this paper, the relation between the bound rubber content and the acid group concentration will be discussed.

\section{$T_{2}$ and Bound Rubber Fractions}

Figure 2 shows the temperature dependence of $T_{2}$ for carbon gel samples (CG-U and CG-O). Here, CG-U and CG-O were prepared from composites of unoxidized carbon black (Carbon Black No. 1) with natural rubber and oxidized carbon black (Carbon Black No. 7) with natural rubber, respectively. Both samples exhibited two $T_{2}$ 's (long and short $T_{2}$ ) above $-40^{\circ} \mathrm{C}$, indicating the existence of two bound rubber components of different mobilities; i.e., tightly and loosely bound rubber components. ${ }^{8,9}$ The long $T_{2}\left(T_{2 \mathrm{~L}}\right)$ for each sample increased rapidly from $-40^{\circ} \mathrm{C}$ to $0^{\circ} \mathrm{C}$ due to the onset of micro-Brownian motion of the loosely bound rubber segments. ${ }^{15} \mathrm{An}$ increase in short $T_{2}$ $\left(T_{2 \mathrm{C}}\right)$ was also observed around $0^{\circ} \mathrm{C}$ in both samples, although this transition was less prominent in the CG-U. Above the transition temperature, both $T_{2 \mathrm{~L}}$ and $T_{2 \mathrm{C}}$ for the CG-O were longer than those for the CG-U. This fact clearly shows that the segmental mobility of both bound rubbers in the

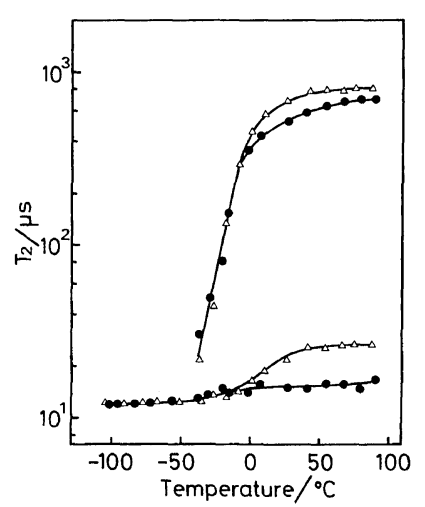

Figure 2. Temperature dependence of $T_{2}$ for carbon gel samples (CG-U and CG-O): 0 , GC-U prepared from a composite of unoxidized carbon black (Carbon Black No. 1) with natural rubber; $\triangle$, CG-O prepared from a composite of oxidized carbon black (Carbon Black No. 7) with natural rubber. 


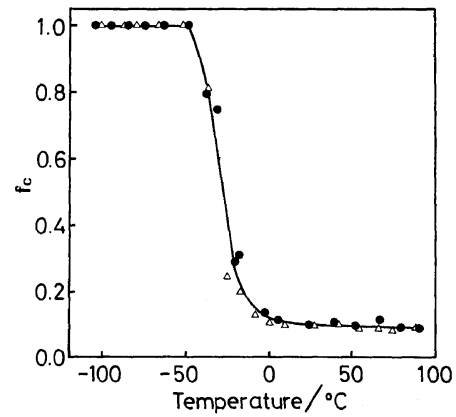

Figure 3. Temperature dependence of the $T_{2 \mathrm{C}}$ component fraction $\left(f_{\mathrm{C}}\right)$ in the total bound rubber. Symbols are shown in Figure 2.

composite prepared from oxidized carbon black and natural rubber is high compared with that prepared from unoxidized carbon black and natural rubber. This suggests that the interactions between the carbon black and natural rubber molecules change with the concentration of acid groups on the carbon black.

Figure 3 shows the $T_{2 \mathrm{C}}$ component fraction $\left(f_{\mathrm{C}}\right)$ in the total bound rubber as a function of temperature for the CG-U and CG-O. Below the $T_{\mathrm{g}}$ of the samples, $f_{\mathrm{C}}$ is 1.0 , since most of the segmental motions of the bound rubbers are frozen. From $-50^{\circ} \mathrm{C}$ to $0^{\circ} \mathrm{C}$, the fraction decreases rapidly, corresponding to the onset of micro-Brownian motion of the loosely bound rubber segments. Even above the $T_{\mathrm{g}}$ of the sample, the $f_{\mathrm{C}}$ exhibited a definite value due to the existence of tightly bound rubber components in the total bound rubber.

As shown in Figures 2 and 3, above $30^{\circ} \mathrm{C}$, the values of $T_{2 \mathrm{C}}, T_{2 \mathrm{~L}}$, and $f_{\mathrm{C}}$ for the samples are almost independent of temperature. A similar temperature dependence of $T_{2 \mathrm{C}}, T_{2 \mathrm{~L}}$, and $f_{\mathrm{C}}$ was found in other carbon gel samples prepared from the composites of various kinds of oxidized carbon blacks (Carbon Black No. 2-6) with natural rubber. Therefore, the $T_{2 \mathrm{~L}}, T_{2 \mathrm{C}}$, and fractions of loosely and tightly bound rubber components at $40^{\circ} \mathrm{C}$ (reference temperature) were used to evaluate the bound rubber structure. In Figure 4, the $T_{2 \mathrm{~L}}$ and $T_{2 \mathrm{C}}$ at $40^{\circ} \mathrm{C}$ are plotted as a function of concentration of total acid groups on the carbon black $\left(C_{\mathrm{f}}\right)$. The increase in $T_{2 \mathrm{~L}}$ and $T_{2 \mathrm{C}}$ with $C_{\mathrm{f}}$ means that the segmental mobility of the loosely and tightly bound rubbers is enhanced by an increase in $C_{\mathrm{f}}$. This suggests that the looseness of the bound rubber is promoted by the introduction

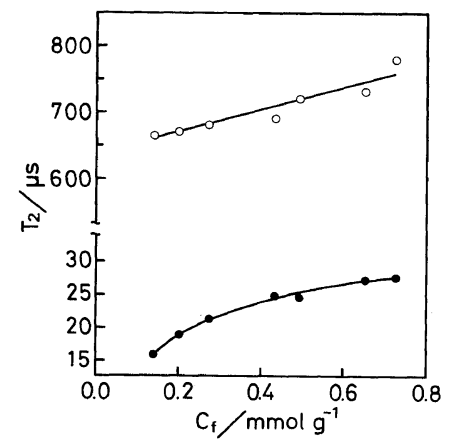

Figure 4. $T_{2 \mathrm{~L}}$ and $T_{2 \mathrm{C}}$ at $40^{\circ} \mathrm{C}$ for the bound rubber as a function of the total acid group concentration $\left(C_{\mathrm{f}}\right): \bigcirc$, $T_{2 \mathrm{~L}} ; \bigcirc, T_{2 \mathrm{C}}$.

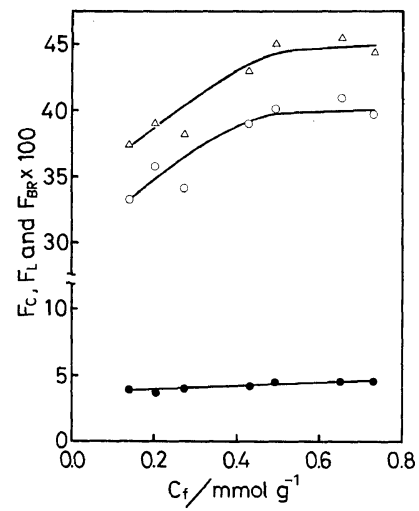

Figure 5. Fractions of total bound rubber $\left(F_{\mathrm{BR}}\right), T_{2 \mathrm{C}}$ $\left(F_{\mathrm{C}}\right)$, and $T_{2 \mathrm{~L}}\left(F_{\mathrm{L}}\right)$ components in the filled rubber at $40^{\circ} \mathrm{C}$ as a function of $C_{\mathrm{f}}: \triangle, F_{\mathrm{BR}} ; \bigcirc, F_{\mathrm{L}} ; \boldsymbol{O}, F_{\mathrm{C}}$.

of acid groups onto the carbon black. Figure 5 shows the fractions of total bound rubber $\left(F_{\mathrm{BR}}\right), T_{2 \mathrm{C}}$ $\left(F_{\mathrm{C}}\right)$, and $T_{2 \mathrm{~L}}\left(F_{\mathrm{L}}\right)$ components in the filled rubber as a function of $C_{\mathrm{f}} . F_{\mathrm{C}}$ and $F_{\mathrm{L}}$ were calculated by the following equation.

$$
F_{\mathrm{C} \text { or } \mathrm{L}}=F_{\mathrm{BR}} \times f_{\mathrm{C} \text { or } \mathrm{L}} \times 100
$$

where $F_{\mathrm{BR}}$ is determined by the solvent extraction method $^{9}$ and $f_{\mathrm{C} \text { or } \mathrm{L}}$ is the fraction of tightly or loosely bound rubber components (short or long $T_{2}$ component) in the total bound rubber. Up to 0.5 mmol $\mathrm{g}^{-1}$ of $C_{\mathrm{f}}, F_{\mathrm{L}}$, and $F_{\mathrm{BR}}$ increase abruptly, followed by a gradual increase with $C_{\mathrm{f}}$. On the other hand, the change in $F_{\mathrm{C}}$ with $C_{\mathrm{f}}$ is less prominent. These results indicate that the increase in $F_{\mathrm{BR}}$ is ascribable for the most part to the increase in the $F_{\mathrm{L}}$. As described previously, oxidation of the carbon 
(A)

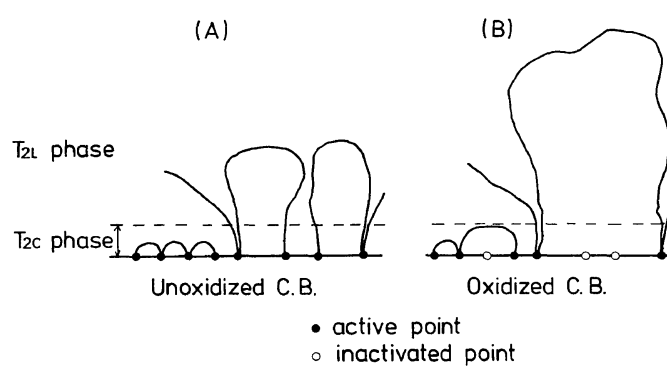

Figure 6. Schematic representations of the bound rubber structures of unoxidized carbon black-natural rubber system (A) and oxidized carbon black-natural rubber system (B).

black did not cause much change in the surface area of the carbon black. Therefore, the large increase in $F_{\mathrm{L}}$ with $C_{\mathrm{f}}$ is considered to be due mainly to the introduction of acid groups onto the carbon black. Gessler reported that the bound rubber content in the composite prepared from the oxidized carbon black and rubber was higher than that prepared from the unoxidized carbon black and rubber. ${ }^{4}$ These experimental results were explained by the enhanced general reactivity of carbon black by oxidation. If an acid group on the carbon black behaves as an active site, the interaction between the carbon black and rubber segments may be enhanced by the introduction of the acid group. In such a case, the segmental mobility of the bound rubber should become more restricted. However, as evident from Figure 4, the segmental mobility of both the loosely and thighly bound rubbers was not restricted but rather enhanced by the introduction of acid groups onto the carbon black. In the present study, the loosely bound rubber phase was not removed by prolonged solvent extraction. This suggests strong interaction between the carbon black and rubber segments even for an oxidized carbon black-rubber system. Papirer et al. ${ }^{16}$ suggest that hydrogen bonded to carbon atoms on the edge of graphitic crystallites in the carbon black is related to the chemisorption of an unsaturated elastomer on the carbon black. If hydrogen atoms are regarded as active sites, the number of these sites decreases with increasing $C_{\mathrm{f}}$. In this case, the average interaction between the carbon black and rubber may decrease, resulting in an increase in the chain mobility of the bound rubber, as evident by the present results. It is considered that the active sites on the carbon black are not acid groups introduced by oxidation but hydrogen atoms bonded to carbon atoms on the edge of graphitic crystallites in the carbon black as suggested by Papirer et al. The $F_{\mathrm{BR}}$ increases with a decrease in the number of active sites on the carbon black. This seems resonable. It has been reported that filled rubber consists of tight and loose folds, cilia, cross linked molecules etc. ${ }^{8}$ In the present study, the enhancement of the segmental mobility in the $T_{2 \mathrm{~L}}$ and $T_{2 \mathrm{C}}$ phases by the incorporation of the oxidized carbon black into natural rubber suggests that an oxidized carbon black-natural rubber system yields bound rubber with fairly long loop molecules. By the incorporation of oxidized carbon black into natural rubber, the number of loops in the $T_{2 \mathrm{~L}}$ and $T_{2 \mathrm{C}}$ phases may decrease due to a reduction in the number of active sites. However, long loop formation may lead to an increase in the total bound rubber content. The schematic representations of the bound rubber structures of the unoxidized carbon black-natural rubber system (A) and the oxidized carbon black-natural rubber system (B) are shown in Figure 6. Hess et al. ${ }^{7}$ found that the adhesion index for the oxidized carbon black-styrene butadiene rubber (SBR) system is extremely low compared with that for an unoxidized carbon black-SBR system. This was explained by the introduction of oxidized carbon black into SBR which induced a decrease in the interaction between the carbon black and the polymer due to a decrease in the number of active sites. This report supports our present considerations.

Acknowledgement. The authors are deeply indebted to Dr. T. Kanamoto for his helpful comments and suggestion in regard to this work.

\section{REFERENCES}

1. C. M. Blow, Polymer, 14, 309 (1973).

2. W. D. Chaeffer and W. R. Smith, Ind. Eng. Chem., 47, 1286 (1955).

3. C. W. Sweitzer, K. A. Burgess, and F. Lyon, Rubber Chem. Technol., 34, 709 (1961).

4. A. M. Gessler, Rubber Age, 94, 598 (1964).

5. A. M. Gessler, Rubber Age, 94, 750 (1964).

6. J. J. Brennan, T. E. Jermyn, and B. B. Boonstra, $J$. Appl. Polym. Sci., 8, 2687 (1964).

7. W. H. Hess, F. Lyon, and K. A. Burgess, Kautscuk und Gummi, Kunststoffe, 20, 3, 135 (1967).

8. J. O'Brien, E. Cashell, G. E. Wardell, and V. J. McBrierty, Macromolecules, 9, 653 (1976).

9. H. Serizawa, M. Ito, T. Kanamoto, K. Tanaka, and 


\section{H. Serizawa et al.}

A. Nomura, Polym. J., 14, 149 (1982).

10. S. Kaufman, W. P. Slichter, and D. D. Davis, J. Polym. Sci., A-2, 9, 829 (1971).

11. T. Nishi, J. Polym. Sci., Polym. Phys. Ed., 12, 685 (1974).

12. J. G. Powles and J. H. Strange, Proc. Phys. Soc., 82, 6 (1963).
13. D. Rivin, Rubber Chem. Technol., 36, 729 (1963).

14. S. Suzuki and K. Miyazaki, Nippon Kagaku Zasshi, 88, 609 (1967).

15. D. W. McCall and D. R. Falcone, Trans. Faraday Soc., 66, 262 (1970).

16. E. Papirer, A. Voet, and P. H. Given, Rubber Chem. Technol., 42, 1200 (1969). 